\title{
STUDY ON PROPERTIES OF SISAL FIBER REINFORCED CONCRETE WITH DIFFERENT MIX PROPORTIONS AND DIFFERENT PERCENTAGE OF FIBER ADDITION
}

\author{
Abdul Rahuman', Saikumar Yeshika ${ }^{2}$ \\ ${ }^{I}$ Assistant Professor, Department of Civil Engineering, SRM University, Tamil Nadu, India \\ ${ }^{2}$ M.Tech, Department of Civil Engineering, SRM University, Tamil Nadu, India
}

\begin{abstract}
The present research was designed to check the workability and strength properties of sisal fiber reinforced concrete with different mix proportions and different percentage of fiber addition. The materials were chosen to improve the various strength properties of the structure to obtain sustainability and better quality structure. Short discrete vegetable fiber (sisal) was examined for its suitability for incorporation in cement concrete. The physical property of this fiber has shown no deterioration in a concrete medium. Fibers were brushed, lined up and cut to obtain $4 \mathrm{~cm}$ length. Degree of workability of concrete mix with $0.2 \%$ super plasticizer and water cement ratio 0.45 had good workability with slump value 53mm and compaction factor 0.88, which is effective, was obtained. Materials were hand mixed with $0.5 \%, 1 \%$ and $1.5 \%$ addition of fiber in M20 and M25 mix design and casted in cubes and cylinders. The obtained specimens were subjected to tests aimed to check the compressive, tensile and flexural strength. An increase in compressive strength by $50.53 \%$ and tensile strength by $3.416 \%$ was observed for $1.5 \%$ addition of fiber in M20 mix design respectively. An increase in compressive strength by $52.51 \%$ and tensile strength by $3.904 \%$ was observed for $1.5 \%$ addition of fiber in M25 mix design respectively.
\end{abstract}

Keywords: Sisal fiber, workability, sustainability, mix design, compressive, tensile, flexural.

\section{INTRODUCTION}

Sisal fiber is a species of Agava. It is botanically known as Agave sisalana. The material is chosen to improve the various strength properties of the structure to obtain sustainability and better quality structure. short discrete vegetable fiber (sisal) was examined for its suitability for incorporation in cement concrete. The physical property of this fiber has shown no deterioration in a concrete medium. Leaves are dried, brushed and baled to form fiber. Concrete is a mixture of glue and fillers, cement and water act as glue and coarse and fine aggregate are the fillers. This concrete is strong in compression and 8 to 10 percentage weaker in tension. Reinforcement is introduced in concrete to improve its property and fibers have always been considered promising as reinforcement of cement.

The main disadvantage is that it is of high price. Addition of fiber reduces workability. Sisal fiber reinforced concrete should be hand mixed.

Sisal fiber reinforced concrete is the concrete with randomly distributed fibers. The failure strength and modulus of elasticity depends on the amount of cellulose and the orientation of the micro-fibers.

This study is done to fine the physical properties of conventional concrete and sisal fiber reinforced concrete and to enhance the properties of concrete using sisal fiber by replacing cement with respective percentage of fiber and finding the strength variation on concrete in different mix proportions.

\section{MATERIALS AND METHODOLOGY}

Fiber was brushed, lined up and cut to obtain $4 \mathrm{~cm}$ length. Then casting and testing of concrete specimens using different ratio of sisal fiber that is $0.5 \%, 1 \%$ and $1.5 \%$.

\subsection{Materials Used}

- $\quad$ Cement Used-OPC

- Cement Specific Gravity-3.15

- Coarse Aggregate Specific Gravity-2.66

- $\quad$ Fine Aggregate Specific Gravity-2.60

- Super Plasticizer- $0.2 \%$ to the weight of cement.

- Water cement ratio-0.45

- Sisal fiber addition- $0.5 \%, 1 \%, 1.5 \%$ to the weight of cement

\subsection{Workability}

To find workability, considerable trial and error method was done using slump cone test to find slump in concrete and compaction factor test to find consistency. Water cement ratio of 0.45 was used.

\subsection{Specimen Preparation}

Materials were hand mixed to obtain the respective M20 and M25 design mix with the respective percentage of fiber addition. The mix designs were then placed in cube and cylinder molds. Demolding was done and specimens were obtained. Curing of the specimen is done until testing was done. 


\subsection{Strength Test}

- Compressive Strength- Cubes were tested for compressive strength using compression testing machine.

- Tensile strength- Cylinders were tested for tensile strength using compression testing machine.

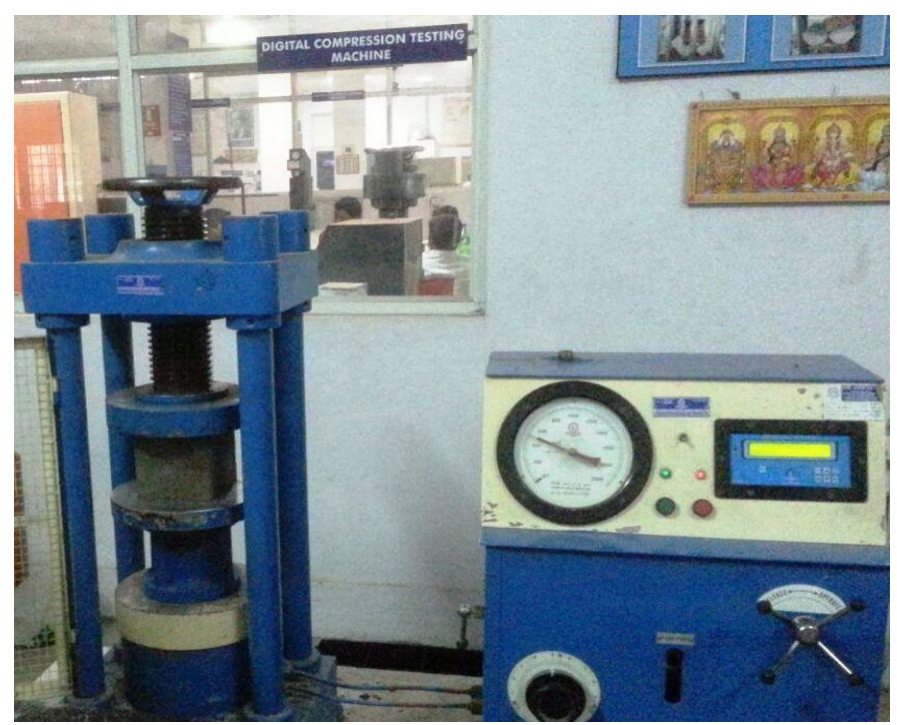

Fig -1: Compression testing machine

\section{RESULTS AND DISCUSSION}

\subsection{Slump Test}

Table -1: Test without super plasticizers and 1.5\% fiber

\begin{tabular}{|l|l|}
\hline Water Cement Ratio & Slump Value in $\mathrm{mm}$ \\
\hline 0.35 & 1 \\
\hline 0.40 & 3 \\
\hline 0.45 & 4 \\
\hline
\end{tabular}

Table -2: Test with super plasticizers and $1.5 \%$ fiber

\begin{tabular}{|l|l|}
\hline Water Cement Ratio & Slump Value in $\mathrm{mm}$ \\
\hline 0.35 & 14 \\
\hline 0.40 & 26 \\
\hline 0.45 & 53 \\
\hline
\end{tabular}

Concrete mixture with $0.2 \%$ super plasticizer and water cement ratio 0.45 had slump $53 \mathrm{~mm}$ which was categorized as good workability.

\subsection{Compaction Factor Test}

Table -3: Test without super plasticizers and $1.5 \%$ fiber

\begin{tabular}{|l|l|}
\hline Water Cement Ratio & Slump Value in $\mathrm{mm}$ \\
\hline 0.40 & 0.842 \\
\hline 0.45 & 0.86 \\
\hline 0.5 & 0.88 \\
\hline
\end{tabular}

Table -4: Test with super plasticizers and $1.5 \%$ fiber

\begin{tabular}{|l|l|}
\hline Water Cement Ratio & Slump Value in $\mathrm{mm}$ \\
\hline 0.40 & 0.92 \\
\hline 0.45 & 0.86 \\
\hline 0.50 & 0.88 \\
\hline
\end{tabular}

Compaction factor was effective for 0.45 water cement ratio with $0.2 \%$ addition of super plasticizers.

\subsection{Compression Test}

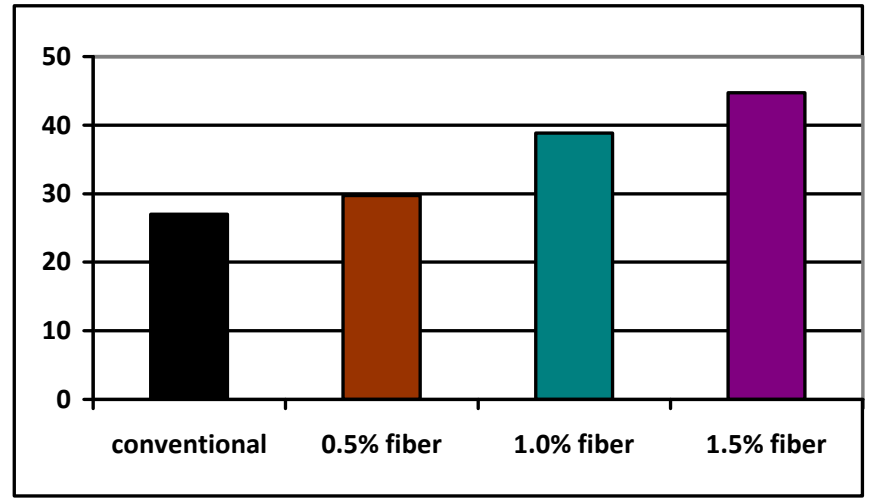

Chart -1: Graphical representation of M20 compressive strength

Table -5: Result of compression strength for M20

\begin{tabular}{|l|l|}
\hline $\begin{array}{l}\text { Percentage Addition } \\
\text { Of Fiber }\end{array}$ & $\begin{array}{l}\text { Percentage Increase } \\
\text { In Strength }\end{array}$ \\
\hline $0.5 \%$ & 0.168 \\
\hline $1 \%$ & 30.83 \\
\hline $1.5 \%$ & 50.53 \\
\hline
\end{tabular}

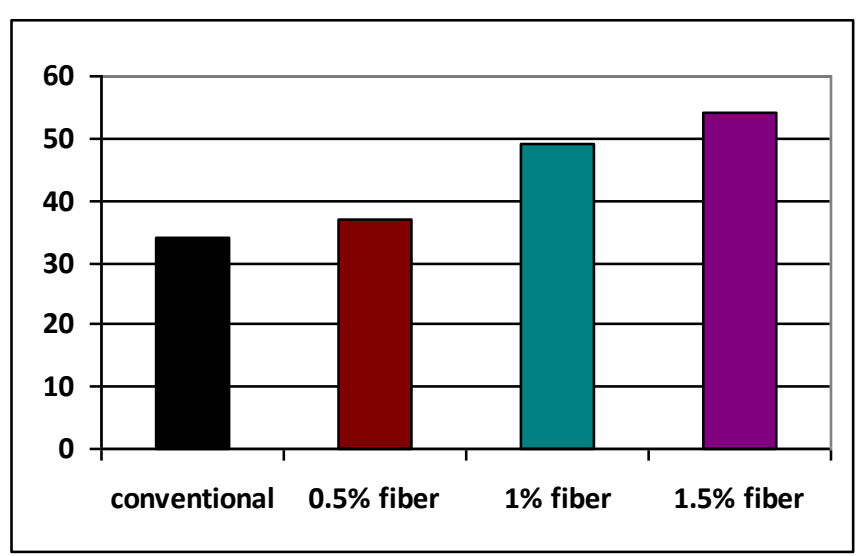

Chart -2: Graphical representation of M25 compressive strength

Table -6: Result of compression strength for M25

\begin{tabular}{|l|l|}
\hline $\begin{array}{l}\text { Percentage Addition } \\
\text { Of Fiber }\end{array}$ & $\begin{array}{l}\text { Percentage Increase } \\
\text { In Strength }\end{array}$ \\
\hline $0.5 \%$ & 4.32 \\
\hline $1 \%$ & 38.33 \\
\hline $1.5 \%$ & 52.51 \\
\hline
\end{tabular}

Addition of $1.5 \%$ fiber in concrete gave almost $50 \%$ increase in compressive strength. 


\subsection{Tensile Strength}

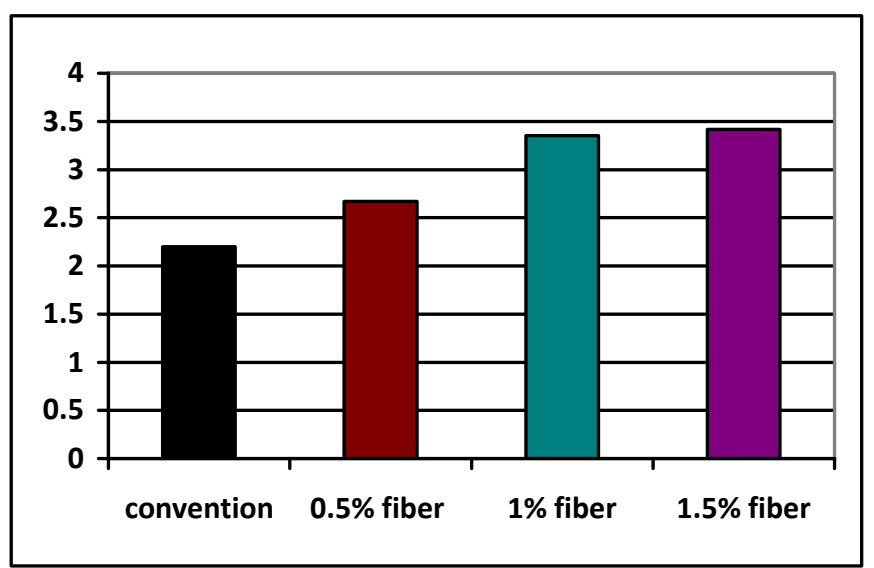

Chart -3: Graphical representation of M20 tensile strength

Table -7: Result of tensile strength for M20

\begin{tabular}{|l|l|}
\hline $\begin{array}{l}\text { Percentage Addition } \\
\text { Of Fiber }\end{array}$ & $\begin{array}{l}\text { Percentage Increase In } \\
\text { Strength }\end{array}$ \\
\hline $0.5 \%$ & 12.65 \\
\hline $1 \%$ & 41.37 \\
\hline $1.5 \%$ & 44.378 \\
\hline
\end{tabular}

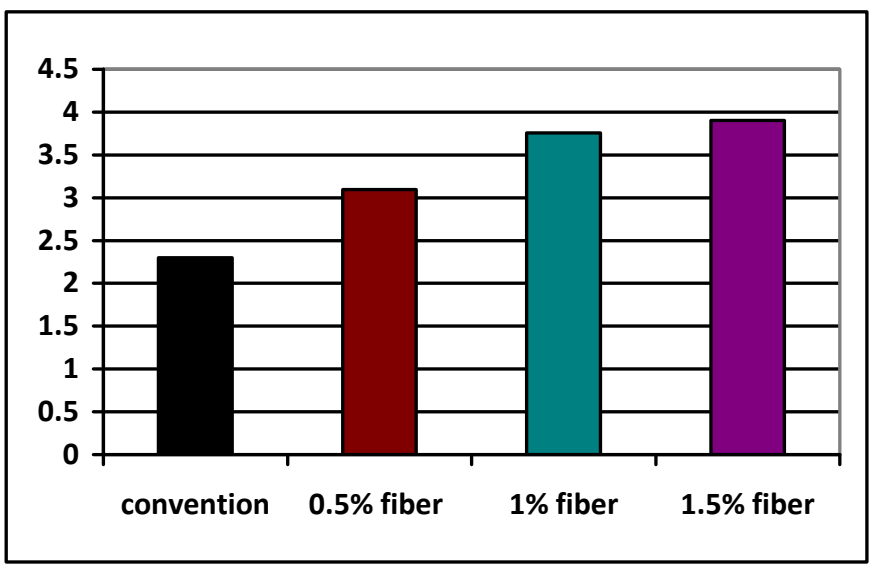

Chart -4: Graphical representation of M20 tensile strength

Table -8: Result of tensile strength for M25

\begin{tabular}{|l|l|}
\hline $\begin{array}{l}\text { Percentage Addition } \\
\text { Of Fiber }\end{array}$ & $\begin{array}{l}\text { Percentage Increase In } \\
\text { Strength }\end{array}$ \\
\hline $0.5 \%$ & 7.944 \\
\hline $1 \%$ & 30.83 \\
\hline $1.5 \%$ & 36.027 \\
\hline
\end{tabular}

Addition of $1 \%$ and $1.5 \%$ of fiber on tensile strength of concrete is almost same.

\subsection{Discussion}

The workability of concrete was affected to a large extend on addition of sisal fiber. Only after addition of super plasticizer to the mix, the appropriate workability was achieved.

There was no much difference in compaction factor as the variation was very minute after the addition of fiber.
According to the study, $1.5 \%$ addition of fiber was more effective on compression strength for both the mix design M20 and M25.

Whereas percentage increase in the tensile strength was comparatively more in M20 than M25.

\section{CONCLUSION}

The study has concluded that there was an increase in slump value from $4 \mathrm{~mm}$ to $53 \mathrm{~mm}$ after addition of super plasticizer. Degree of workability for concrete mixture with $0.2 \%$ super plasticizer and water cement ratio 0.45 provided good workability.

Compaction factor increases by 0.02 to 0.03 after addition of super plasticizer.

Compression strength increased by $50.53 \%$ after addition of $1.5 \%$ fiber for M20 mix design, whereas the increase was up to $52.51 \%$ for the same percentage addition of fiber in M25.

Tensile strength increment was almost same for $1 \%$ and $1.5 \%$ addition of fiber. The increased tensile strength for M20 mix design with $1 \%$ and $1.5 \%$ addition of fiber was $41.37 \%$ and $44.378 \%$. There was a decrease in percentage increase in tensile strength for M25 when compared with M20. The increase in tensile strength for M25 mix design with $1 \%$ and $1.5 \%$ addition of fiber is $30.83 \%$ and $36.027 \%$.

It is concluded that $1.5 \%$ addition of fiber will give better strength

\section{ACKNOWLEDGEMENTS}

I wish to express my sincere thanks to the management, Dr.T.P.Ganesan, ProVice Chancellor (P\&D), Dr.C.Muthamizhchelvan, Director (E\&T), Dr.R.Annadurai, Professor and Head, Department of Civil Engineering, SRM University for providing all the facilities for carrying out this work.

I express my sincere thanks to Project Coordinator, Dr.V.Thamilarasu, Professor, Mr.S.Abdul Rahuman, Assistant Professor, for their valuable guidance, suggestion and source of inspiration throughout this project.

I express my deep love and warm regards to my family and friends for their support, constant encouragement and timely help.

The authors can acknowledge any person/authorities in this section. This is not mandatory.

\section{REFERENCES}

[1]. H. S. Ramaswamy, B. M. Ahuja and S. Krishnamoorthy (1983) Behaviour of concrete reinforced with sisal,jute, coir and bamboo fibres. 
[2]. Tara Sen, H. N. Jagannatha Reddy (2011)

Application of sisal, bamboo, coir and jute natural composites in structural up grading.

[3]. Yanki Wu, Yanbin Li \& Bin Niu (2014) Assessment of the mechanical properties of sisal fibre-reinforced silty clay using traxial shear tests.

[4]. F. Silva and Dr. R. D. T. Filho (2004) Sisal fibre reinforcement of durable thin walled structures- A new perspective.

[5]. Romildo Dias Toledo Filho, Kuruvilla Joseph and Khosrow Ghavami (1999) The use of sisal fibre as reinforcement in cement based composities.

[6]. R. S. P. coutts \& P. G. Warden(1992) Sisal Pulp reinforced cement mortor.

\section{BIOGRAPHIES}

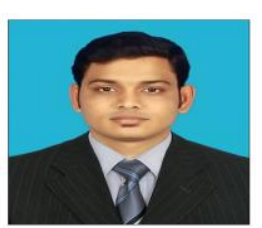

Assistant Prof. S.Abdul Rahuman, Department of civil engineering, SRM University, Kattangulathur, Chennai.

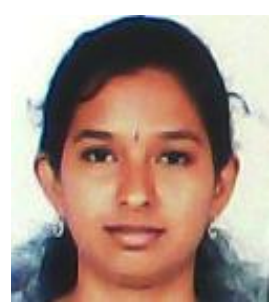

Saikumar.Yeshika, Department of civil engineering, SRM University, Kattangulathur, Chennai 